\title{
Novel Insight into the Quality of Assessment of Physicians
}

\section{Brett Snodgrass*}

Dr Social Ltd, USA

\begin{abstract}
In the United States of America, medical regulation of physicians is overseen by state medical boards (SMBs). SMBs are considered to be the gatekeepers of the medical practice. They ensure that only competent physicians are licensed and practicing, and they make certain that doctors act in a professional manner. To effectively regulate the practice of medicine, an SMB must have sufficient knowledge to discern between negligent or unwarranted patient care, and the provision of excellent care. This report, from Missouri, describes the repeated failure of the State Board of Registration for the Healing Arts (SBRHA) in distinguishing safe and effective coronary artery stenting from unnecessary stenting. The SBRHA repeatedly demonstrated a critical lack of competent medical knowledge. Their staff committed conduct, which was unethical and fraudulent, and were not given proper supervision by physicians. The SBRHA intentionally misrepresented important evidence to make their court case appear more robust than it actually was. They also tried to have the testimony from their expert witness stricken from the record because it did not support their case. This report highlights a fundamental failing of medical regulation by the SBRHA, and policy makers would be prudent to consider legislative reform of medical regulation.
\end{abstract}

Keywords: Health politics; Governance; Licensing; Accreditation; Health policy and administration; Politics; Competency

\section{Introduction}

In the United States of America (USA), state medical boards (SMBs) are legislatively established to ensure that only competent physicians are practicing medicine and that those physicians act in a professional manner [1]. Typically, the enforcer of laws, rules, and regulations needs to understand and be compliant with them. Thus, an SMB should be able to demonstrate a range of medical knowledge broad enough to discern between competent and negligent patient care. Similarly, SMBs should demonstrate professional conduct, as they are the assessors of physician professionalism. This report describes the numerous efforts to discipline interventional cardiologist, Antoine Adem, MD, by the Missouri (MO) State Board of Registration for the Healing Arts (SBRHA). This took place during the years of 2012-2014 for events, which occurred from 2008-2010 [2-4]. It describes an SMB's scientifically unmeritorious, underhanded, and relentless efforts to punish a physician for providing excellent patient care.

\section{Case Report}

The relevant events began in March 2008, when Dr. Adem's decision to place a stent in one of Patient S.B.'s coronary arteries was called into question by the Medical Care Appraisal Committee (MCAC) of MO's Jefferson Regional Medical Center (JRMC) [3]. The MCAC obtained external review of S.B.'s records, and on May 21, 2008, the hospital's medical executive committee (MEC) requested Dr. Adem provide responses to concerns raised by the reviewers. On July 7, 2008, Dr. Adem wrote a letter purportedly from cardiologist Dr. Timothy Catchings, referred to as the "Catchings letter," and gave it to the JRMC CEO, Dr. Lloyd Ford. The letter was written on Dr. Catchings' letterhead and had a forgery of Dr. Catchings' signature. The letter claimed Dr. Adem's decision for percutaneous coronary intervention with stent placement of Patient S.B. was a reasonable decision [3]. The Catchings letter listed criteria from the American College of Cardiology 2005 guidelines for percutaneous coronary intervention as evidence that supported Dr. Adem's decision to place a coronary stent in Patient S.B. In addition, the patient improved after Dr. Adem placed the coronary stent. Thus, this safe and successful intervention affirmed the applicability of the guidelines which state: "Class IIa [class of recommendation] (Weight of evidence/opinion is in favor of usefulness/efficacy.) It is reasonable that PCI be performed in patients with CCS [Canadian Cardiovascular Society] class III angina and single-vessel or multivessel CAD who are undergoing medical therapy and who have 1 or more significant lesions in 1 or more coronary arteries suitable for PCI with a high likelihood of success and low risk of morbidity or mortality. (Level of Evidence: B)" [5]. An inquiry of Dr. Catchings at Missouri University Medical Center revealed that he did agree with the medical care as described in the forged letter [3]. However, the JRMC MEC decided to revoke hospital privileges from Dr. Adem for unethical conduct in forging Dr. Catching's signature on a letter to Dr. Ford, and for allegedly providing negligent medical care [6]. The law requires that a doctor who loses clinical privileges must report it to the SBRHA. On September 23, 2010, Dr. Adem sent a letter to the SBRHA informing them about his forgery of the Catchings letter [3]. As part of the hospital by-laws, Dr. Adem was able to have a hearing with another committee known as the Hospital Review Committee (HRC). On June 7, 2011, the HRC concluded that Dr. Adem's provision of patient care was appropriate and that he engaged in unethical conduct by creating the Catchings letter [6]. The HRC voted 2:1 that Dr. Adem's privileges be reinstated, and their recommendation was given to the MEC that possessed final decision-making authority. The MEC decided not to follow the HRC's suggestion and terminated Dr. Adem from the hospital. Given Dr. Adem's admission to forging a letter, and the HRC's determination that Dr. Adem provided appropriate patient care, one might expect that the issue would be quickly resolved. On April 3, 2012, the SBRHA filed a complaint with the MO Administrative Hearing Commission (AHC) seeking to discipline Dr. Adem for XI counts. Counts VI, VII,

${ }^{*}$ Corresponding author: Brett Snodgrass, MD, Clinical Management Consultant Dr Social Ltd., 468 N Camden Drive, Suite 200, Beverly Hills, California, 90210, United States, Tel: 1916 893-1722; E-mail: brett@drsocial.org

Received December 06, 2015; Accepted December 30, 2015; Published January 20, 2016

Citation: Snodgrass B (2016) Novel Insight into the Quality of Assessment of Physicians. Health Care: Current Reviews 4: 155. doi: 10.4172/2375-4273.1000155

Copyright: ( 2016 Snodgrass B. This is an open-access article distributed under the terms of the Creative Commons Attribution License, which permits unrestricted use, distribution, and reproduction in any medium, provided the original author and source are credited. 
and VIII were voluntarily dismissed by the SBRHA on May 31, 2013. Count I claimed Dr. Adem committed unethical conduct for forging the Catchings letter. Counts II, III, IV, V, and IX were five disciplinary claims, each for the alleged inappropriate placement of a coronary artery stent or stents in one of five different patients. On April 17, 2014, Commissioner Sreenu Dandamudi deemed that Dr. Adem's license was subject to discipline for forging Dr. Catchings' signature on the letter that Adem gave to Dr. Ford on July 7, 2008 [3]. This ruling did not start the discipline but meant that discipline was to be imposed by the SBRHA. Dr. Adem had another meeting with the SBRHA. On November 24, 2014, the SBRHA issued a public reprimand of Dr. Adem's medical license [4]. As part of the public reprimand, Dr. Adem was required to inform all hospitals and clinics where he worked that he had been reprimanded [4]. Although the final discipline of a public reprimand for Count I may seem appropriate, the course by which the SBRHA arrived at that outcome is, in the words of Commissioner Dandamudi, "perversely ironic [sic]" [2].

\section{Deviation from evidence-based regulation}

It is unclear how SBRHA formed the false inference that the coronary artery stent placements by Dr. Adem were negligent and unnecessary. The SBRHA cited no peer-reviewed literature or scholarly work in support of their claims of negligent patient care. In 1999, Nishioka et al. reported findings from a study that evaluated intravascular ultrasounds' (IVUS') ability to assess the significance of epicardial coronary artery stenosis [7]. They found that a lesion luminal area of $\leq$ four square millimeters $\left(\mathrm{mm}^{2}\right)$ is a simple and "highly accurate criterion for significant coronary narrowing." Identification of significant coronary narrowing is a prerequisite for coronary stenting.

The SBRHA's efforts to discipline Dr. Adem for the allegedly inappropriate patient care was unmeritorious as none of the five patient's six epicardial coronary arteries had a lesion luminal area of more than four $\mathrm{mm}^{2}$ [2]. Count II against Dr. Adem was for alleged negligent and unwarranted medical care of 45 -year Patient E.O. The patient had a stent placed in the left anterior descending coronary artery (LAD) that had a luminal area of $3.4 \mathrm{~mm}^{2}$, and a stent placed in the right coronary artery (RCA) that had a luminal area of $2.9 \mathrm{~mm}^{2}$. Count III against Dr. Adem alleged negligent care for his stenting of 70year Patient L.M.s mid-LAD that had a luminal area of $2.8 \mathrm{~mm}^{2}$. Count IV alleged Dr. Adem negligently placed a stent in 53-year Patient J.E.'s mid-LAD that had a luminal area of $3.7 \mathrm{~mm}^{2}$. Count $\mathrm{V}$ was intended to discipline Dr. Adem for placing a stent in 68-year Patient P.J.s midLAD that had a luminal area of $3.8 \mathrm{~mm}^{2}$. Although the SBRHA dropped counts VI, VII and VIII, they did not drop all of their grossly inaccurate claims of negligent care. Count IX intended to discipline Dr. Adem for placing a stent in 52-year Patient J.N.s LAD that had a luminal area of $3.1 \mathrm{~mm}^{2}$. Since the SBRHA asserted Dr. Adem provided negligent care to five different patients, they continued their abuse of Dr. Adem and filed Count $\mathrm{X}$ asserting that he had committed repeated negligence [2]. Count XI alleged that Dr. Adem was willfully and continually performing unnecessary procedures. A government agency that regulates the practice of medicine should be able to discern negligence, repeated negligence, and unnecessary procedures from appropriate patient care. However, the SBRHA demonstrated profound ignorance by their repeated failure to competently assess the appropriateness of coronary stenting for five different patients.

On September 24, 2013, Commissioner Dandamudi issued a report of proposed findings and facts of law [2]. In the proposed report he dismissed Counts I, II, III, IV, V, IX, X, and XI against Dr. Adem. The only change between the September 24, 2013, proposed report and the final April 17, 2014, ruling was regarding the latter's decision not to dismiss Count I $[2,3]$. Commissioner Dandamudi dismissed the SBRHA's allegations of negligent care as follows, "SBR [SBRHA] alleges that on the basis of the charges in Counts II, III, IV, V and IX in the Complaint, cause exists to discipline Dr. Adem's license pursuant to $\$ 334.100 .2$ RSMo on the basis of 'repeated negligence.' SBR has presented no evidence that any of the patients in Counts II, III, IV, V and IX ever complained about the care they received from Dr. Adem, that there were any complications during or after their procedures, or that they are even aware that the care Dr. Adem provided them is forming the basis of charges against Dr. Adem. SBR also presented no evidence that the procedures described in Counts II, III, IV, V and IX were unnecessary or harmful to the patients whose procedures formed the basis of those complaints" [2].

Commissioner Dandamudi's 2013 proposed report further illustrates the severity of the misconduct by the SBRHA. In the report Commissioner Dandamudi described the SBRHA's conduct as "unfathomable and deeply disturbing [sic]," "wholly unworthy of a state agency [sic]," and suggested that the SBRHA may have committed fraud [2]. After the SBRHA's expert witness Dr. Jonathan Tobis gave deposition opposing their claims of negligence, the SBRHA tried to have everything related to him stricken from the court record so that they could punish Dr. Adem for providing care that their witness Dr. Tobis did not report as negligent or unwarranted. Commissioner Dandamudi wrote the following of the State Board of Registration (SBR): "In the July 10, 2013 Hearing, SBR [SBRHA] moved to strike all references to the testimony of its expert, Dr. Tobis. It is clear from the record that SBR did not introduce and did not want to introduce Dr. Tobis' deposition testimony because it did not support the allegations in the Complaint against Dr. Adem" [2].

Further questions about the objectivity and integrity of the SBRHA are raised because they had to get Commissioner Dandamudi to extend their pre-arranged deadline for the taking of depositions from the expert witnesses [3]. The SBRHA's failure to comply with the initial deadline may be secondary to their inability to find a cardiologist who agreed with their unfounded, unscientific, and whimsical assertions that Dr. Adem provided unsafe patient care. Cardiologists Dr. Bouhasin and Dr. Ahmad both testified to the appropriateness of Dr. Adem's care for the five patients, and they both disagreed with all of the SBRHA's allegations of inappropriate patient care.

Commissioner Dandamudi wrote the following about the dismissal of Dr. Kern's deposition from the record, "The July 2, 2013 Order excluding the testimony of Dr. Kern... was based solely on the SBR's [SBRHA's] acknowledged deficiency ... in Dr. Kern's testimony and its unreasonable tardiness, well outside the time frame set forth in the Scheduling Order... the Board had ample time to prepare for hearing. However, the Board failed to do so until three weeks prior to a hearing that was scheduled eight months earlier at the request of both parties... In his Motion in Limine, Dr. Adem argued in part that Dr. Kern's deposition testimony did not state and SBR did not adduce exactly what records Dr. Kern relied on to form the basis of his opinions in this case... Dr. Kern could not produce necessary evidence for crossexamination that Dr. Kern claimed he relied on. The SBR attempted to cure these deficiencies by attempting to take an additional deposition of Dr. Kern on July 5, 2013 just a few days before the scheduled hearing. Allowing the SBR to take another deposition of its expert months after the deadline for such depositions and just a few days prior to the scheduled hearing would have significantly prejudiced Dr. Adem. 
Excluding the unreliable testimony of Dr. Kern was an appropriate decision based on the circumstances" [2].

The SBRHA planned to use Morton Kern, MD, as an expert witness, but his deposition was ultimately stricken from the record because no one was aware of how or why he arrived at his conclusions. Thus, four cardiologists including Dr. Adem supported the care provided by Dr. Adem. In contrast to the competent and reliable testimony of the cardiologists that supported Dr. Adem, neither Dr. Kern nor the SBRHA was able to specify which particular documents and images Dr. Kern relied on to form his assessment. After failing to communicate with Dr. Kern and appropriately ascertain what documents he used to render his opinions during the deposition, the SBRHA sent him a FedEx package of documents and records. Again, and without effective clinical communication, they were sent back to the SBRHA.

Commissioner Dandamudi wrote the following about the SBRHA's post hoc efforts made during the July 2013 hearing to try to improve Dr. Kern's April 2013 deposition "Indeed, during the offer of proof, Dr. Kern was unable to state with certainty whether the material SBR [SBRHA] sent him [via FedEx] was what he had previously reviewed and relied on to form the basis of his opinion" [2]. According to Leonard et al. "effective communication and teamwork is essential for the delivery of high quality, safe patient care" [8]. Legislators and health care reform activists may be interested in encouraging policies and laws that ensure the SMBs are composed of those that can communicate and work in teams effectively. In spite of over eight months to prepare to depose a cardiologist for the trial, the SBRHA could not perform one competent deposition with accurate documents of a physician that supported their claims of negligence.

\section{Commissioner Dandamudi further wrote}

"What is particularly egregious about SBR's [SBRHA's] 'offer of proof' [made during the July 2013 trial] is that it is completely inconsistent with Dr. Kern's April 18, 2013 deposition testimony. This Commission need not look any further than the first patient case, patient E.O., to determine that the offer of proof is grossly inaccurate at best and a fraudulent misrepresentation to this Commission at worst. In his deposition on April 18, 2013, Dr. Kern was specifically asked the following regarding what he reviewed in the patient E.O. case, 'the only materials that you reviewed prior to issuing this February 22nd, 2010, report and prior to providing your testimony today were the two cardiac catheterization reports, one with the stress test, one without, and two CD-ROM disks of angiographic procedures.' Dr. Kern answered 'correct' in response to this question about his review of patient E.G.'s case. However, SBR in its offer of proof regarding what Dr. Kern relied on in formulating his opinion in the E.O. case (see SBR Exhibit 6), submitted approximately 40 pages of medical records that he did not list as records he relied on in his deposition testimony.

"How SBR expects this Commission to reconcile the plain language of what Dr. Kern said he relied on to formulate his opinion in the patient E.O. case with what is included in Exhibit 6 is unfathomable and deeply disturbing. Specifically, SBR Exhibit 6 includes a Procedure Log, office note, and Complete Patient Report, none of which Dr. Kern indicates that he relied on. SBR's 'offer of proof' in Exhibits 4-8 appear to be nothing more than a conscious attempt to make Dr. Kern's review more robust than what it actually was. This Commission notes that SBR's blatant mischaracterization of the materials that Dr. Kern reviewed is an affront to this tribunal and reflects, at best, recklessness that is wholly unworthy of a state agency" [2].
The commissioner also wrote that the SBRHA committed, "what seems to be an intentional mischaracterization of important evidence" [2]. It is presumably true that the SBRHA was acting in a manner that they believed to be the interest of the public. However, their false belief of practitioner negligence persisted in spite of extensive evidence to the contrary and no competent evidence supporting their allegations of unwarranted procedures. The SBRHA's fixed, false belief appears to have contributed to their grossly unethical, unsound, and reckless conduct.

\section{Discussion}

The SBRHA tried to frame Dr. Adem several times by 1) an attempt to conceal the testimony of their expert witness Dr. Tobis, 2) by misrepresenting what documents their other expert witness, Dr. Kern reviewed, 3) by trying to depose Dr. Kern a second time a mere five days before the hearing at the AHC which could prevent Dr. Adem from effectively cross-examining him, and 4) by fabricating false claims of negligent care based on no apparent scientific rationale. According to Chaudhry et al., physicians are given due process by SMBs $[1,9]$. However, this report of fraudulent or fraudlike regulation by the SBRHA demonstrates that licensees are not always afforded the "luxury" of due process. Furthermore, the SBRHA's conduct is unconscionable as they made extensive effort to try to frame Dr. Adem. The SBRHA tried to conceal the exculpatory deposition of Dr. Tobis, filed blatantly dishonest and scientifically unmeritorious claims alleging unsafe patient care in court, and intentionally mischaracterized the medical records reviewed by Dr. Kern [2].

One definition of discipline is "to punish or penalize in order to train and control" [10]. Other than the broad and somewhat vague claim of "protecting the public," the role of physician discipline by SMBs has not been clearly espoused by regulators [9]. This case raises several questions about the functions of SMBs and their role in physician discipline. First, what might disciplining Dr. Adem for providing good care train him to do? Second, is the SBRHA protecting the public by issuing a public reprimand to Dr. Adem more than six years after the incident? Dr. Adem gave the Catchings letter to Dr. Ford of the MEC on July 7, 2008. Dr. Adem was publicly reprimanded by the SBRHA on November 24, 2014 [4]. Third, since the information about the forged letter was already public knowledge, how might a "public reprimand" be expected to increase patient safety $[4,6]$ ? Fourth, since Dr. Adem was already extremely remorseful for forging the Catchings letter, will a public reprimand teach him to change his behavior [4,6]? Fifth, if a single act of misrepresentation or fraud is a threat to the public, should consideration be given to the need to discipline the members of the SBRHA for their deceptive regulatory conduct and efforts to frame Dr. Adem [2]? Sixth, if clinical incompetence or repeated negligence is a threat to the safety of the public, is it concerning that none of the eight doctors on the SBRHA demonstrated sufficient medical knowledge to either know that Dr. Adem's provision of care was appropriate or to learn that it was appropriate [2]? Is the safety of the public at risk considering that every physician on the SBRHA failed to apply the knowledge of the cardiac stenting guidelines to the care of Dr. Adem's patients [2,5]? Each of the six coronary arteries that Dr. Adem stented had a luminal area of less than four $\mathrm{mm}^{2}$ by IVUS [7]. Seventh, why did no physician on the SBRHA stop the attorneys from pursuing glaringly false litigation after their witness Dr. Tobis gave an exculpatory deposition on behalf of Dr. Adem? Eighth, if communication is an important competency of physicians, then why did no physician on the SBHRA ask Dr. Adem about his therapeutic rationale? According to Berwick, "crystal clear expectations about the unacceptability of disruptive and disrespective behaviors" is essential to improve the triple aim of improved patient outcomes, better population health, and more affordable care [11]. 
The SBRHA's disruption of the practice of medicine was profound, and investigation and research into the causes of the unacceptable regulatory conduct are needed. There may be conflicts of interest involving the SMB attorneys who are paid hourly and rewarded instead of punished for filing false claims in court. Policy makers might consider the societal burden that a dysregulated, clinically ignorant SMB places on the public. The SBRHA's harassment of doctors that provide excellent patient care has several negative effects. First, it prevents patients from seeing their physician, as it will likely require them to spend a significant amount of time trapped in depositions, obtaining expert witnesses, and working alone or with their attorney to file myriad rebuttals to the plethora of dishonest claims filed by the SMB. Second, by reducing the number of healthcare providers, it does not decrease the cost of care. Third, the societal burden of paying attorneys more than $\$ 100$ per hour to litigate for years either raises the cost of the licensure fee or is a burden on taxpayers. In addition to the attorneys, there are numerous costs that Including a commissioner, expert witnesses, and the myriad of staff needed to process the frivolous claims. Unfortunately, society obtains no reward on investment and does not become safer in spite of hundreds of thousands of dollars being spent on the SBRHA's litigatory whims. Fourth, the perverse discipline teaches physicians that their provision of excellent patient care can be punished by forcing them into years of litigation with a government agency that is not above filing numerous blatantly false claims in court.

The harm that results from the egregiously deceptive and ignorant actions committed by the SBRHA's attorneys is compounded by the failure of the physician board members to provide oversight. This can lead persons to believe that physicians disciplined by the SBRHA were given proper peer review instead of being victims of fraud. The poorly communicating and inattentive physicians are more akin to a mindless rubber stamp that often does not check to see if what their attorneys are filing in court is consistent with the high-quality medical evidence. The integrity and excellence mentioned in the SBRHA's newsletter is an illusion resulting from their detached personnel, abysmal state of medical knowledge, and payments that increase linearly with their dishonesty [12]. Ignorance is indeed bliss for those medical regulators and their staff that are paid for their harassment of good clinicians such as Dr. Adem.

\section{Conclusion}

The quality of assessment of physicians by medical regulators is an untapped area of health systems research that offers the opportunity myriad novel findings. Future researchers might examine how legitimate and fraudulent regulatory actions each contribute to the quality and safety of healthcare. Some may argue that it is necessary for SMBs to be cautious when evaluating the care provided by physicians. The statement is true, but committing fraud is not cautious, it is unethical, and it punishes those that provide good care while wasting hundreds of thousands of dollars. This case clearly illustrates that the "experts," are often far less accurate than those who consider evidence-based medicine $[2,5,7]$. Dr. Adem endured years of harassment because of the ignorance of those on the SBRHA. The doctors on the SBRHA could have perused the medical literature to form an educated opinion about the appropriateness of Dr. Adem's decisions to place coronary artery stents in the five patients [5,7]. In general, SMBs should be required to provide scientific literature with their allegations of incompetence to prevent similar acts of regulatory misconduct in the future. The SBRHA committed numerous acts of deception that were far more egregious than Dr. Adem's creation of the Catchings letter. In addition, their regulatory misconduct and frivolous litigation wasted hundreds of thousands of dollars. What message about safety should stakeholders take away from situations where the licensee is more ethical and competent than the entirety of the SBRHA? Disciplinary actions, even fraudulent actions result in national and international effects secondary to the robust communication system between regulators [9].

The physicians of the MO SBRHA have repeatedly demonstrated regulatory misconduct, ignorance, attempted concealment, misrepresentation, ineffective communication, gross negligence, and fraud. Further investigation and study of regulatory misconduct by SMBs is critical to determine its extent and impact. Is MO alone, or are other SMBs "protecting" the public through fraudulent regulation? Future studies are needed to evaluate the quality of medical regulation and the effects that a disruptive regulator has on the quality of medical care.

\section{Conflicts of interest}

The author reports no financial conflict of interest. Dr. Snodgrass reports he was denied a medical license in 2013 by the Missouri SBRHA. The author was surprised at the matter and reviewed their past cases. What he discovered forms the basis for this report as well as other ongoing scholarly works.

\section{Acknowledgements}

The author would like to thank Helen Nguyen for her paid editorial assistance for making minor grammatical changes.

\section{References}

1. Chaudhry HJ, Gifford JD, Hengerer AS (2015) Ensuring competency and professionalism through state medical licensing. JAMA 313: 1791-1792.

2. Commission MAH (2013) State Board of Registration for the Healing Arts v Adem, No. 12-0526 HA (Sept. 24, 2013). Accessed Jan. 20, 2016.

3. Commission MAH (2014) State Board of Registration for the Healing Arts v Adem, No. 12-0526 HA (Apr. 17, 2014). Accessed Jan. 20, 2016.

4. Arts MBoRftH (2014) State Board of Registration for the Healing Arts v. Adem, 2010-002086 (Nov. 24, 2014). Accessed Jan. 20, 2016

5. Smith SC, Feldman TE, Hirshfeld JW, Jacobs AK, Kern MJ, et al. (2006) ACC AHA/SCAI 2005 Guideline Update for Percutaneous Coronary Interventionsummary article: a report of the American College of Cardiology/American Heart Association Task Force on Practice Guidelines (ACC/AHA/SCA Writing Committee to Update the 2001 Guidelines for Percutaneous Coronary Intervention). Circulation 113: 156-175.

6. http://mo.findacase.com/research/wfrmDocViewer.aspx/xq/ fac.20121113 0002014.EMO.htm/qx Adem v. Jefferson Mem'l Hosp. Ass'n (E.D. Mo., 2012). Accessed Jan. 20, 2016.

7. Nishioka T, Amanullah AM, Luo H, Berglund H, Kim CJ, et al. (1999) Clinical validation of intravascular ultrasound imaging for assessment of coronary stenosis severity: comparison with stress myocardial perfusion imaging. J Am Coll Cardiol 33: 1870-1878.

8. Leonard M, Graham S, Bonacum D (2004) The human factor: the critica importance of effective teamwork and communication in providing safe care. Qual Saf Health Care 13 Suppl 1: i85-90.

9. Johnson DA, Chaudhry HJ. (2012) Medical Licensing and Discipline in America Lanjam, MD: Lexington Books.

10. http://dictionary.reference.com/browse/discipline Discipline. Online Etymology Dictionary. Accessed Jan. 20, 2016

11. Berwick DM (2015) Postgraduate education of physicians: professional selfregulation and external accountability. JAMA 313: 1803-1804.

12. Arts, MBoRftH (2015) Healing Arts News. 29: 1-20. (Apr. 1, 2015). Accessed Jan 20, 2016. 